\section{Latest resulits show urgent need to address child restraint use}

To the Editor: Road traffic crashes are the leading cause of morbidity and mortality in children in South Africa (SA), ${ }^{[1]}$ and are preventable through implementing a systems approach to address the causes. Proper education, child passenger legislation and enforcement of the law are priority actions. It is well known that properly employed seatbelts and child restraints reduce the risk of serious injury and death to children. However, despite campaigns such as 'Arrive Alive' to increase the use of child restraints, a 2008 observational study conducted by Red Cross War Memorial Children's Hospital (RCWMH) in Cape Town, SA, found that a majority of adults and children entering the hospital gates did not use such restraints. ${ }^{[2]}$ It is possible that this was because there was no appropriate child restraint law.

In late 2014, SA promulgated its amendment to regulation 213, section 6A of the National Road Traffic Act No. 93 of $1996,{ }^{[3]}$ which mandates child restraints to be used for children less than 3 years of age travelling in a motor vehicle (this came into force in April 2015). We therefore repeated the observational survey at the main gates of RCWMCH in August 2018 to determine whether there had been a change in restraint use since the legislation had been modified. The methodology we used closely followed that of Kling et al. ${ }^{[2]}$ in order to provide a consistent comparison between the 2008 count and that of 2018.

Vehicles were observed between the hours of $05 \mathrm{~h} 45$ and $09 \mathrm{~h} 00$ in the morning on three weekdays in August 2018. If restraint use was not visible or was unclear for any reason, the entire car was excluded. All drivers were considered adults, and other age groups were approximated into the broadly defined age groups of baby, child, teen or adult. To minimise potential differences in judgement between data collectors, a single person was posted at the gate of RCWMCH for the time periods mentioned.

The 2018 study observed a total of 1761 people, including 215 children, travelling in 1249 cars entering the main gates. For adults, restraint use was $65 \%$ overall $(n=1003)$, an increase from $50 \%$ in 2008. Restraint use by backseat adult passengers remained low at $17 \%(n=105)$.

For children, only $18 \%(n=38)$ had some form of restraint, which is $7 \%$ more than in 2008 . Of these, $12 \%(n=25)$ were in an appropriate child restraint - an increase of $4 \%$ over the 10 -year period. Sadly, $33 \%$ of children $(n=71)$ were observed sitting unrestrained on an adult's lap, an increase on the 2008 figure (Fig. 1).

Overall, the results show a slight but insignificant increase in the use of child restraints among children arriving at RCWMCH, even 3 years after the legislation changed. This finding aligns with Ferreira and van $\mathrm{As}^{\prime} \mathrm{s}^{[1]}$ analysis of surveillance data from the RCWMCH trauma unit from 1991 to 2016 , which shows that $73 \%$ of road traffic collision cases involved unrestrained children. However, it may not be representative of all children being transported in Cape Town, as parents may feel the need to hold their sick children rather than putting them in a restraint. An observational survey conducted at various points in the city would provide more solid evidence of current use.

Evidence from other countries shows that child restraint laws are effective when paired with a comprehensive approach including

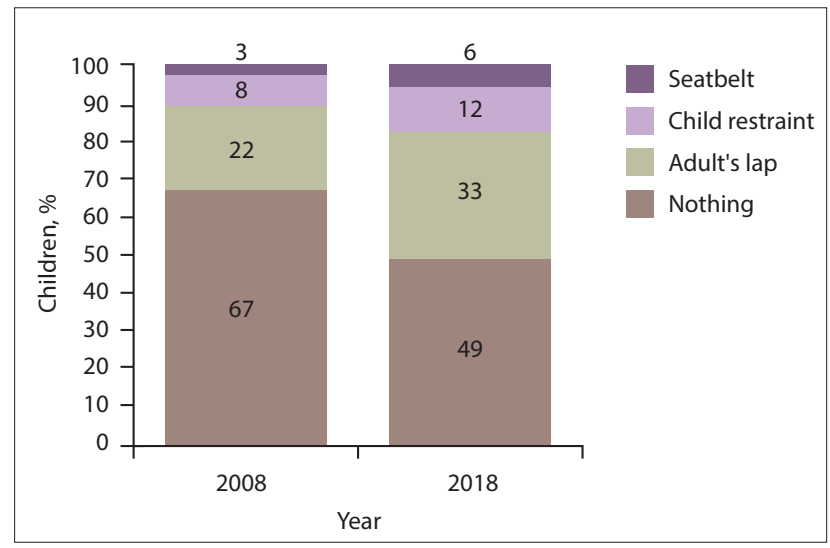

Fig. 1. Child restraint use in $2008(\mathrm{n}=313)$ and $2018(\mathrm{n}=215)$.

education campaigns and enforcement. For example, in Australia, a programme to educate on, distribute and offer fitting for restraints in low-socioeconomic early childhood education centres increased correct use. ${ }^{[4]}$

Additionally, adult seatbelt use is important to monitor and enforce, because studies have shown that children's risk behaviour decisions involving seatbelts are strongly influenced by those of their parents. ${ }^{[5]}$

National legislation alone has not been shown to be effective. Local authorities need to augment enforcement. Hospitals, healthcare providers and paediatricians need to become more involved in educating parents and children alike. The future of all citizens in SA depends on a comprehensive effort to increase seatbelt and child restraint use.

\section{Carson Clay, A B Sebastian van As}

Childsafe South Africa, Red Cross War Memorial Children's Hospital and Department of Paediatric Surgery, Faculty of Health Sciences, University of Cape Town, South Africa

ceclay@princeton.edu

\section{Kate Hunter}

George Institute for Global Health, University of New South Wales, Sydney, Australia

\section{Margaret Peden}

George Institute for Global Health, Oxford, UK

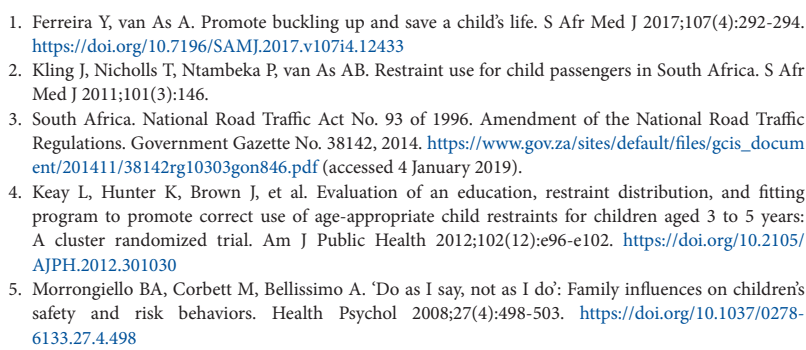
https://doi.org/10.7196/SAMJ.2017.v107i4.12433

2. Kling J, Nicholls T, Ntambeka P, van As AB. Restraint use for child passengers in South Africa. S Afr Med J 2011;101(3):146.

3. South Africa. National Road Traffic Act No. 93 of 1996. Amendment of the National Road Traffic Regulations. Government Gazette No. 38142, 2014. https://www.gov.za/sites/default/files/gcis_docum ent/201411/38142rg10303gon846.pdf (accessed 4 January 2019).

4. Keay L, Hunter K, Brown J, et al. Evaluation of an education, restraint distribution, and fitting program to promote correct use of age-appropriate child restraints for children aged 3 to 5 years: A cluster randomized trial. Am J Public Health 2012;102(12):e96-e102. https://doi.org/10.2105 AJPH 2012301030

5. Morrongiello BA, Corbett M, Bellissimo A. 'Do as I say, not as I do': Family influences on children's safety and risk behaviors. Health Psychol 2008;27(4):498-503. https://doi.org/10.1037/02786133.27.4.498

S Afr Med J 2019;109(2):66. DOI:10.7196/SAMJ.2019.v109i2.13831 